\title{
Review Article \\ The Visual Brain, Perception, and Depiction of Animals in Rock Art
}

\author{
Derek Hodgson \\ Department of Archaeology, University of York, Kings Manor, York Y01 7EP, UK \\ Correspondence should be addressed to Derek Hodgson; dehogson@googlemail.com
}

Received 17 May 2013; Accepted 7 July 2013

Academic Editor: Ravi Korisettar

Copyright (C) 2013 Derek Hodgson. This is an open access article distributed under the Creative Commons Attribution License, which permits unrestricted use, distribution, and reproduction in any medium, provided the original work is properly cited.

Several aspects of the depiction of animals in rock art can be explained by certain perceptual correlates relating to the visual brain and evolutionary factors. Recent evidence from neuroscience and the visual brain not only corroborates this claim but provides important new findings that can help delineate which graphic features relate to biological/genetic criteria. In addition to highlighting how the insights from visual science and evolutionary studies can promote a greater understanding of the depictive strategies employed to portray animals, this paper will also explore ways in which the findings from these disciplines can be assimilated with semiotics that provide novel insights into the preference for depicting animals in a particular format over an extended period. The emphasis throughout is placed on dual-inheritance theory where culture and evolutionary determinants are seen as complementary.

\section{Introduction}

It is becoming increasingly clear that the immense period during which animals were depicted in palaeoart, as well as their universality, is unable to be adequately accounted for by cultural factors [1-3]. The obvious similarity in the way animals were depicted across widely separated and divergent cultures suggests that the influence of more prevailing factors may be relevant. In this respect, animals can potentially be portrayed in a myriad of ways but were depicted in a relatively stereotyped fashion over long periods throughout the world. Moreover, recent research has shown cultural explanations need to be regarded with caution as it has been shown that spots applied to depicted Upper Palaeolithic horses, which were once believed to be shamanistic in origin, probably represent natural dapples $[4,5]$. Moreover, the many distortions that typify depicted animal in rock art (see, e.g., Figure 1) can be reliably explained by perceptual and cognitive processes rather than cultural conventions [6]. These findings that provide further support to the notion FrancoCantabrian depictions portrayed real animals produced by keen observers of fauna $[2,7-9]$.

The necessity to rapidly detect and identify animals has consequences for understanding the preoccupation with animals and their portrayal in rock art. For example, this is predominantly in contour profile [2], which is a phenomenon that can be found in such diverse locations as China, Australia, Africa, and Europe [10] from the time when two-dimensional depictions appeared around 35,000 bp (see Figures 1, 2, 3, 4, 5, and 6). Such pervasiveness derives from the way the visual brain functions, which was crucial to the survival of hominins $[2,3]$.

\section{Perceptual Precursors}

Since presenting copious evidence from neuroscience, perception, and evolutionary psychology supporting the previous claim $[2,3,9]$, further corroboration has continued to accumulate from relevant scientific disciplines. This research has revealed that the primary goal of vision is first to detect then identify objects in the environment. Thus, many animals, including predators and prey, employ avoidance strategies by utilizing camouflage to conceal themselves. In these scenarios, colour and texture remain secondary to shape, although the former may allow fine tuning once an animal has been recognised as such [11]. Shape refers to global properties of an object that remain constant despite changing conditions [12] that takes precedence because it contains various kinds of important information for detecting 


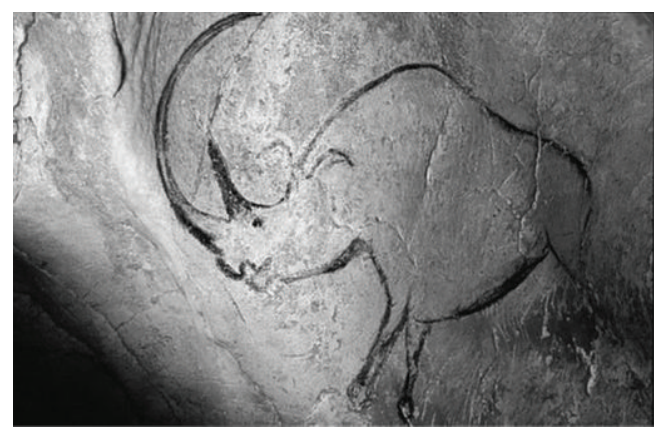

Figure 1: Outline of a Rhinoceros from Chauvet Cave, France, up to 30,000-year old showing the sideways view in outline with prominent defining features exaggerated. The ears, however, appear to be based on a local convention.

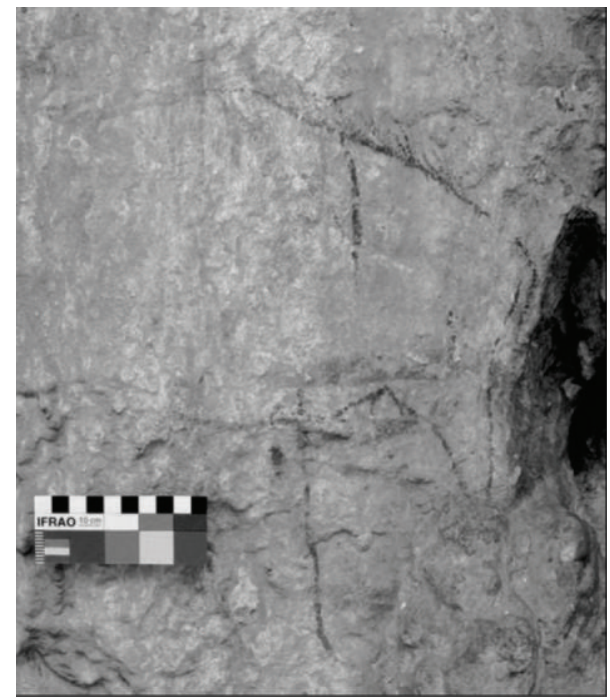

FIgURE 2: Early rock art from China (Jinsha River, Northwest Yunnan) of a bison possibly dating up to 8,000-year ago that shows similarities with bison depictions from European Upper Palaeolithic cave art (reprinted from Figure 10, [10]).

and identifying animals. For hominins, the detection of camouflaged animals during the majority of the Pleistocene was crucial to survival to the extent that fundamental visual properties necessary for their identification became "hard wired" in the brain. This is supported by the fact that humans respond to camouflage displays in a similar way to animals [11]. Moreover, the human brain possesses a dedicated neural structure in the temporal cortex for the recognition of animals [13-16].

The preference for detecting animals is reflected in change blindness where alterations to animals (and people) are identified more rapidly and accurately than to plants or artificial objects [17]. Moreover, animals are monitored more acutely for changes to their state and location than other objects, which is an automatic response of the visual recognition system. These findings suggest a specialised finely tuned system for categorising and attending to animals that is a consequence of selection pressure.

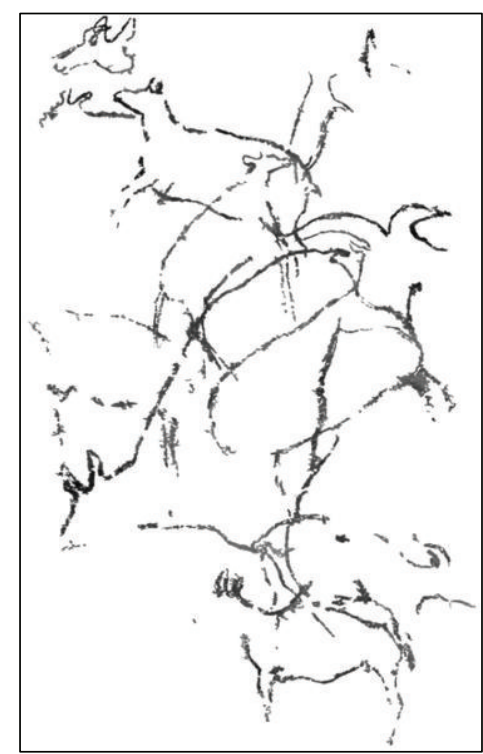

Figure 3: Early rock art from China (Jinsha River, Northwest Yunnan) showing overlapping sideways views of animal outlines similar to those of European Upper Palaeolithic art as well as other parts of the world (reprinted from Figure 15, [10]).

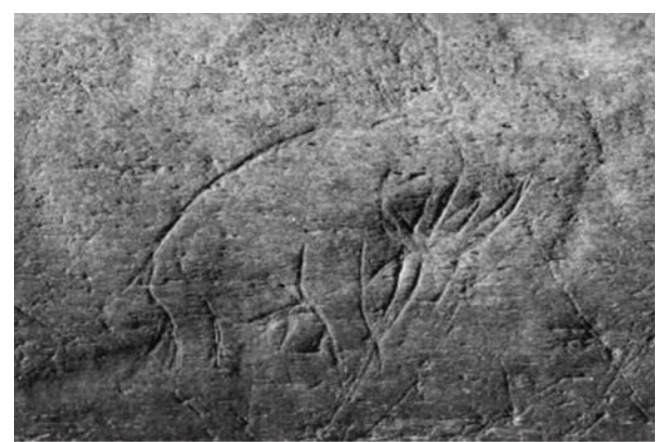

FIGURE 4: Earliest art of America around 13,000-year old of a Proboscidean incised on a mineralized animal bone from Vero Beach, Florida (reprinted from Figure 1(b), Purdy et al. [18]).

\section{Diagnostic Cues and the Typical Viewing Profile}

Mithen [20] has shown that the traditional hunters pay special attention to salient parts of animals. This is supported by the fact that incoming information regarding animals is processed by preattentive mechanisms along both the ventral and limbic/emotional visual pathways, which tags diagnostic features that are disposed towards outline shape rather than colour and texture [21]. Studies of the visual system's preference for visual outline shape actually utilise outline drawings of animals similar to those found in palaeoart. Moreover, when viewing conditions are degraded, the visual system of humans (and monkeys) relies on coarse visual information (i.e., the shape profile) for identifying an animal at the superordinate level [22]. In sum, the sideways profile view of animals is regarded as the most generalised, effective, and 


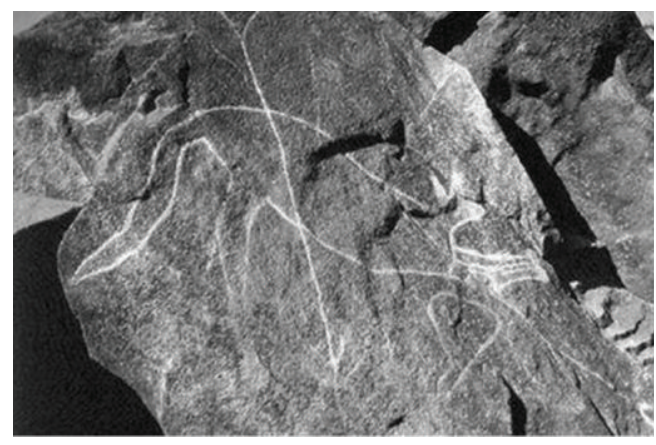

FIgURE 5: Rock Art from Burrup area, in the National Heritagelisted Dampier Archipelago showing outline of animal where some of Australia's oldest figurative depictions exist.

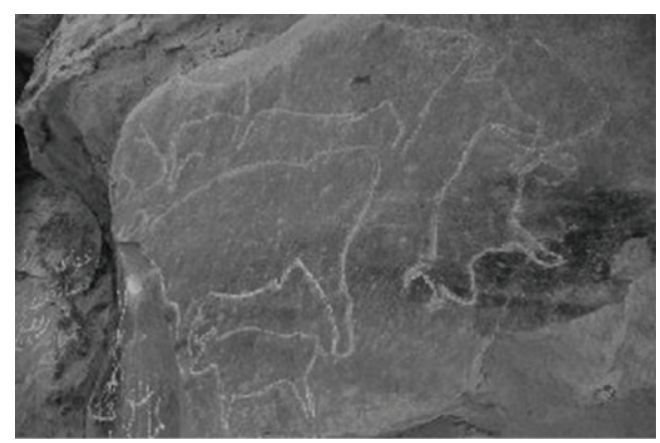

FIGURE 6: Egyptian Rock Art: a panel with eight bovids at Qurta I (QI.2.1) dated to around 15,000 years ago that is similar to European Upper Palaeolithic depictions of animals (reprinted from Figure 5, Huyge et al. [19]).

dependable means of identifying an animal despite changes to viewing angle because visual imagery and memory are subject to internal storage and processing economy that still needs to be highly diagnostic $[23,24]$.

Thus, the raw diagnostic cues, for example, head, eyes, neck, back, mouth, and so forth, pertaining to animals progress through the visual system automatically and compellingly direct the attention of the perceiver, as to ignore such cues would be dangerous. It is not, however, until preattentive diagnostic cues are matched with higher level conscious visual information that full recognition of an animal occurs, which takes place through visual memory/imagery, which is able to fill in the gaps of the fragmentary cues to provide the full outline profile (the iconic representation). As Delorme et al., [25] specify.

It seems thus that, in such rapid categorization tasks, the subjects might base their responses on the global aspect of the target and the processing of one or several intermediate features that are diagnostic of the target category. The subjects could prime the processing of pertinent intermediate features through top-down influences, and such biases could result in faster object processing.

Thus, in processing canonical views of animals, the visual system takes from the target shape the maximum number of available diagnostic lower-order features that help facilitate immediate detection. These are then matched with already accumulated information in higher-order visual imagery/memory which allows an image of an object to be held in mind and confirms what lower-order feature components may suggest. Imagining an object is also useful when the prevailing sensory stimulus is ambiguous as this helps bias perception through expectation [26]. In other words, visual imagery can prime perception. Hunter-gatherers needed to constantly employ visual imagery in order to search and identify both predator and prey. In circumstances where environmental signals are ambiguous, the visual system therefore possesses the advantage of being readily primed to regard any camouflaged feature or ambiguous surface (such as a rock face) with the slightest suggestion of fauna as an animal, which is consistent with the human visual system tendency to complete partial figures.

\section{Outlines}

Not only can the sideways canonical view of depicted animals in rock art be explained by the perceptual factors relating to the visual brain, but also the almost universal utilisation of the contour outline for depicting fauna [27]. It seems that those responsible for producing rock art had an implicit awareness that the drawn line economically delineates objects in the world in the same way as this has recently been established by neuroscience for the visual system [28]. In fact, the neural activity of the visual system in response to viewing line drawings is virtually the same as when coloured photographs are viewed, which indicates that line drawings capture the most important elements of a scene. Again, colour and texture were found to be incidental to recognition. Moreover, it was established that, even when $75 \%$ of the outline was removed from a line drawing, the depicted object could still be identified [28]. Recovering the outline of a three-dimensional natural form is held to be the one of the main ways the visual system is able to detect animals, especially when camouflaged [12], and suggests this is the primary reason outline is widespread in rock art. The ability to recognize objects from depleted outlines begins early in human development as 2-year olds are able to "fill in" depleted outline drawing by projecting an imaginary template onto such drawings for the purpose of identification [28]. Interestingly, chimpanzees are unable to perform this task, due to a lack in the neural capacity required.

It might be argued that many animals are depicted as silhouettes (but still in sideways view). However, Halverson [1] has shown that silhouettes serve as a means of highlighting external contours by accentuating figure and ground-an important early perceptual feature. Moreover, the external contour is invariably drawn first after which the figure is then filled in. Silhouetted animal depictions, along with contour outlines, make up the majority of the depiction of animals in early southern African rock art.

Other factors relating to constraints defined by either perceptual or motor determinants concern the direction of the profile view (either left or rightwards facing) whereby 
a right-handed individual would be expected to portray animals facing left due to ergonomics. As a significant majority of individuals in any community are right-handed, one would therefore expect the left facing view to be more prevalent. However, throughout rock art, both views tend to be equally represented that suggests perceptual determinants override physiomotor factors. The lack of preference in direction can be potentially addressed by what is known as "virtual views," which is a perceptual phenomenon that exploits the redundancy of animal form, where the same information is encapsulated in the two separate profile views [2].

Due to the compelling nature of the previous perceptual factors, it would therefore have been more likely that the corresponding graphic components were transmitted culturally, thereby enhancing the universality of the depictive strategies involved.

\section{The Indexical and Iconic}

As the incoming diagnostic cues for animals, for example, head, eyes, neck, back, mouth, and so forth, are processed preattentively in the early to intermediate visual cortex, these cues correspond to Peirce's indexical signs [29], which are snippets of information that, through association, signal a particular object. In processing visual information, the indexical seems to take precedence over the iconic, as the former is a preconscious response based on a fragmentary visual cue towards which one is obliged to react in the first instance literally through "blind compulsion" that is, based on associative learning procedures for avoiding danger and promoting survival. Thus, blind compulsion refers to the fact that indexical signs have a direct physical association with an object that tends to spontaneously direct attention. In fact, indexical signs constitute the most common way animals respond to stimuli from the world [30] in that indexes point towards what an object is by way, for example, of simple features that provoke a response for example, a spot or line that moves in a certain direction (possible indicating an insect), certain smells, or particular sounds that are specific to a species' evolutionary past. Indexical signs are therefore more naturally assimilated than the iconic and predominate throughout nature [31] whereas the iconic relies on interpretation and tends to be acquired later. In effect, the conscious mental image constitutes the actual iconic sign that provides ultimate confirmation of what exists in reality [32] and which dynamically interacts with lowerorder preattentive indexical cues. In this sense, the indexical sign can be regarded as more basic and fundamental than the iconic [33] in that it signalled not only the presence of a predator or prey but also intent, for example, where an animal may be concealed. Animal parts accordingly acted as clues to various aspects of animal behaviour towards which early humans needed to be keenly aware in order to survive by making inferences on the basis of indexical cues [30]. Although animals utilize both indexical and iconic signs, humans additionally respond to and function within a framework of indexical, iconic, and abstract symbolic signs which are actively engaged and manipulated [30, 34]. In short, the indexical served as a pars pro tot and a more compelling indication than the iconic because it provides the initial clues as to the status of an animal.

This scenario is supported by the fact a neural pathway exists that links the visual cortex to the limbic (emotional) brain for the rapid detection of animals, which evolved for instant flight or for capturing prey $[13,16]$. Importantly, Yang et al. [35] found that the human amygdala (in the emotional brain) responds more to stimuli denoting animals than any other object irrespective of stimulus presentation (whether pictures or associated sounds), which reflects the critical importance for the rapid perception of animals in human evolution. This propensity can be related to the unique human ability for anthropomorphizing where animals are often socialised-a capacity that fails when the amygdala is damaged [36]. The existence of a powerful emotionally driven neural substrate for perceiving animals, which facilitates blind (indexical) compulsion, may help explain the widespread obsession with the depiction of fauna in rock art.

Although this scenario is played out in the context of the functioning visual system, it has interesting correspondences with the actual production of graphic images in that creating iconic depictions is more complex than making indexical marks. This is because icons need to conform to that which is being represented through a high degree of resemblance and are therefore constrained by the signifier whereas indexes merely require one aspect or element from a situation to be pertinent. This is perhaps why so many fragmentary parts of animals are found in rock art throughout the world, particularly in cave art where the undulating walls suggest various animal parts that act as indexical cues to the full iconic animal outline. This may also help to explain why so many hand prints and stencils are also a worldwide phenomenon as they served as indexical signs of human presence that are much easier to produce than a complete iconic depiction of the human figure. Hand prints/stencils seem to be more numerous than the depiction of animals even at the time when figurative representation first emerged precisely because they are relatively easy to produce [37]. The realisation of their significance may have originated in the use and handling of ochre for which there is evidence at least as early as 300,000 years ago [38]. The hands of those using ochre would have become smeared in such pigment inevitably leading to accidentally produced hand prints on various surfaces that would have been noticed as such. In addition, when butchering freshly killed animals, the hunters' hands unavoidably become covered in blood, which could also have served as a source of hand prints. Hand prints can thereby be integrated into the animal/human dynamic in that they probably originated in the butchering of animals that became associated with ochre (which is also red) and intentionally produced hand prints. Although hand prints may be more prolific than the depiction of animals, there is a step change from simply printing or drawing round the hand to the actual portrayal of animals. In this regard, it is notable that some of the earliest depictions of animals from various caves in Upper Palaeolithic Europe are made up entirely of hand prints. 


\section{Discussion}

Hodgson [2] has described the mental template for identifying animals as a quasi "sign stimulus" in that this template was so critical for the rapid identification of animals it became integral to the visual brain. Thus, long-term evolutionary influences were reinforced by the ongoing everyday interaction with animals that meant it was inevitable animals would come to be depicted in the way described. The direct neural pathway from the visual cortex to the limbic/emotional brain for detecting animals also suggests that animals feature frequently in rock art precisely because they induce a strong emotional response related to survival. Based on these insights, it is valid to conclude that the depiction of animals was constrained by evolutionary prerogatives that had shaped the visual brain. This does not mean that animal representations derive purely from biological substrates as this would imply areas of the cortex evolved for the purpose of depicting animals. Rather, the evolutionary forces that had created the visual brain served to canalise the way depictions were configured. In this sense, early rock art can be said to emulate the underlying neurocognitive mechanisms. By showing that the subject matter of animals as well as the way they were depicted are mainly determined by neurovisual/perceptual imperatives, several enduring aspects of animal depiction can thereby be accounted for. From this perspective, sociocultural factors continue to be relevant as the nuances applied to the basic sideways outline view can be explained accordingly. For example, the ears of the depicted rhinoceros in Figure 1 appear to be one such nuance [39]. This suggests a more productive approach to understand the way animals were depicted in rock art is through dualinheritance theory where cultural influences are regarded as complementing evolutionary effects. In this sense, certain key aspects of how animals are depicted stem from the need to rapidly identify animals that were especially relevant to hunter gatherer communities but which could be potentially amended according to changing priorities as communities became more sedentary and culturally driven through the growing influence of niche construction.

\section{Conclusion}

The fact that animals constitute the most common subject in rock art and are depicted mostly in outline sideways view suggests representation depended on the way the visual brain detects and identifies fauna. Although these insights apply mainly to hunter-gatherer rock art, much the same influence can be found in the depiction of animals in art from more sedentary groups and much later periods-though there is a greater degree of variability in the latter cases due to the growing influence of cultural imperatives that comes with increasing population levels, specialisation, and extensive niche construction.

\section{References}

[1] J. Halverson, "The first pictures: perceptual foundations of Paleolithic art," Perception, vol. 21, no. 3, pp. 389-404, 1992.
[2] D. Hodgson, "The biological foundations of upper Palaeolithic art. Stimulus: percept and representational imperatives," Rock Art Research, vol. 20, no. 1, pp. 3-22, 2003.

[3] D. Hodgson and P. A. Helvenston, "The emergence of the representation of animals in Palaeoart: insights from evolution and the cognitive, limbic and visual systems of the human brain," Rock Art Research, vol. 23, no. 1, pp. 3-40, 2006.

[4] M. Pruvost, R. Bellone, N. Benecke et al., "Genotypes of predomestic horses match phenotypes painted in Paleolithic works of cave art," Proceedings of the National Academy of Sciences of the United States of America, vol. 108, no. 46, pp. 18626-18630, 2011.

[5] G. Bar-Oz and S. Lev-Yadun, "Lev-Yadun, Paleolithic cave rock art, animal coloration, and specific animal habitats," Proceedings of the National Academy of Sciences of the United States of America, vol. 109, no. 20, Article ID E1213, 2012.

[6] J. A. Cheyne, L. Meschino, and D. Smilek, "Caricature and contrast in the upper palaeolithic: morphometric evidence from cave art," Perception, vol. 38, no. 1, pp. 100-108, 2009.

[7] R. D. Guthrie, "Ethologicial observations from Palaeolithic art," in La contribution de la zoologie et de l'ethologie à l'interpretation de l'art des peuples chasseurs préhistoriqùes, H. Bandi, W. Huber, M. R. Sauter, and S. Bitter, Eds., 3e Colloque de la Société Suisse des Sciences Humaines, pp. 35-74, Éditions Universitaires Fribourg, Fribourg, Switzerland, 1974.

[8] S. C. Hudson, “The hunter's eye: visual perception and Palaeolithic art," Archaeological Review from Cambridge, vol. 15, no. 1, pp. 95-109, 1998.

[9] D. Hodgson, "Seeing the "unseen": fragmented cues and the implicit in palaeolithic art," Cambridge Archaeological Journal, vol. 13, no. 1, pp. 97-106, 2003.

[10] P. S. C. Taçon, L. Gang, Y. Decong et al., "Naturalism, nature and questions of style in Jinsha River Rock Art, Northwest Yunnan, China," Cambridge Archaeological Journal, vol. 20, no. 1, pp. 6786, 2010.

[11] T. Troscianko, C. P. Benton, P. G. Lovell, D. J. Tolhurst, and Z. Pizlo, "Camouflage and visual perception," Philosophical Transactions of the Royal Society B, vol. 364, no. 1516, pp. 449461, 2009.

[12] Z. Pizlo, 3D Shape: Its Unique Place in Visual Perception, MIT Press, Cambridge, Mass, USA, 2008.

[13] A. Caramazza and J. R. Shelton, "Domain-specific knowledge systems in the brain: the animate-inanimate distinction," Journal of Cognitive Neuroscience, vol. 10, no. 1, pp. 1-34, 1998.

[14] A. Caramazza and B. Z. Mahon, "The organization of conceptual knowledge: the evidence from category-specific semantic deficits," Trends in Cognitive Sciences, vol. 7, no. 8, pp. 354-361, 2003.

[15] B. Z. Mahon and A. Caramazza, "Concepts and categories: a cognitive neuropsychological perspective," Annual Review of Psychology, vol. 60, pp. 27-51, 2009.

[16] P. A. Chouinard and M. A. Goodale, "Category-specific neural processing for naming pictures of animals and naming pictures of tools: an ALE meta-analysis," Neuropsychologia, vol. 48, no. 2, pp. 409-418, 2010.

[17] J. New, L. Cosmides, and J. Tooby, "Category-specific attention for animals reflects ancestral priorities, not expertise," Proceedings of the National Academy of Sciences of the United States of America, vol. 104, no. 42, pp. 16598-16603, 2007.

[18] B. A. Purdy, K. S. Jones, J. J. Mecholsky et al., "Earliest art in the Americas: incised image of a proboscidean on a mineralized 
extinct animal bone from Vero Beach, Florida," Journal of Archaeological Science, vol. 38, no. 11, pp. 2908-2913, 2011.

[19] D. Huyge, M. Aubert, H. Barnard et al., "Lascaux along the Nile: late pleistocene rock art in Egypt," Antiquity, vol. 81, no. 313, 2007, http://antiquity.ac.uk/ProjGall/huyge/index.html.

[20] S. J. Mithen, "Looking and learning: upper Palaeolithic art and information gathering," World Archaeology, vol. 19, no. 3, pp. 297-327, 1988.

[21] J. H. Elder and L. Velisavljević, "Cue dynamics underlying rapid detection of animals in natural scenes," Journal of Vision, vol. 9, no. 7, article 7, 2009.

[22] M. J. M. Macé, A. Delorme, G. Richard, and M. Fabre-Thorpe, "Spotting animals in natural scenes: efficiency of humans and monkeys at very low contrasts," Animal Cognition, vol. 13, no. 3, pp. 405-418, 2010.

[23] S. E. Palmer, E. Rosch, and P. Chase, "Canonical perspective and the perception of objects," in Attention and Performance IX, J. Long and A. Baddeley, Eds., pp. 135-151, Lawrence Erlbaum Associates, Hillsdale, NJ, USA, 1981.

[24] V. Blanz, M. J. Tarr, and H. H. Bülthoff, "What object attributes determine canonical views?” Perception, vol. 28, no. 5, pp. 575599, 1999.

[25] A. Delorme, G. Richard, and M. Fabre-Thorpe, "Key visual features for rapid categorization of animals in natural scenes," Frontiers of Psychology, vol. 1, no. 21, pp. 1-13, 2010.

[26] J. Pearson, C. W. G. Clifford, and F. Tong, "The functional impact of mental imagery on conscious perception," Current Biology, vol. 18, no. 13, pp. 982-986, 2008.

[27] J. M. Kennedy and J. Silver, "The surrogate functions of lines in visual perception: evidence from antipodal rock and cave artwork sources," Perception, vol. 3, no. 3, pp. 313-322, 1974.

[28] D. B. Walther, B. Chai, E. Caddigan, D. M. Beck, and L. Fei-Fei, "Simple line drawings suffice for functional MRI decoding of natural scene categories," Proceedings of the National Academy of Sciences of the United States of America, vol. 108, no. 23, pp. 9661-9666, 2011.

[29] C. S. Peirce, Collected Writings, Harvard University Press, Cambridge, Mass, USA, 1974.

[30] T. A. Sebeok, "Indexicality," in Peirce and Contemporary Thought: Philosophical Inquirie, K. L. Ketner, Ed., pp. 222-242, Fordham University Press, New York, NY, USA, 1995.

[31] K. Kull, "The architect of biosemiotics: Thomas A. Sebeok and biology," in Semiotics Continues To Astonish: Thomas A. Sebeok and the Doctrine of Signs, P. Cobley, J. Deely, K. Kull, and S. Petrilli, Eds., pp. 233-250, De Grutyer Mouton, Berlin, Germany, 2011.

[32] W. Nöth, "Semiotic foundations of iconicity in language and literature," in The Motivated Sign: Iconicity in Language and Literature 2, O. Fischer and M. Nänny, Eds., pp. 17-28, Benjamins, Philadelphia, Pa, USA, 2001.

[33] J. A. Cheyne, "Signs of Consciousness: Speculation on the Psychology of Palaeolithic Graphics (Part 11)," 1993, http:// watarts.uwaterloo.ca/ acheyne/signcon2.html.

[34] W. Nöth, "Semiotics for Biologists," in Biosemiotics: Information, Codes and Signs in Living Systems, M. Barbieri, Ed., pp. 141-153, Nova Science, New York, NY, USA, 2007.

[35] J. J. Yang, M. Francis, P. S. F. Bellgowan, and A. Martin, "Object concepts and the human amygdala: enhanced activity for identifying animals independent of in-put modality and stimulus format," in Proceedings of the 12th Annual Meeting of the Cognitive Neuroscience Society, New York, NY, USA, 2005.
[36] A. S. Heberlein and R. Adolphs, "Impaired spontaneous anthropomorphizing despite intact perception and social knowledge," Proceedings of the National Academy of Sciences of the United States of America, vol. 101, no. 19, pp. 7487-7491, 2004.

[37] D. Hodgson, "Altered States of consciousness and palaeoart: an alternative neurovisual explanation," Cambridge Archaeological Journal, vol. 16, no. 1, pp. 27-37, 2006.

[38] L. S. Barham, "Systematic pigment use in the middle pleistocene of South-Central Africa," Current Anthropology, vol. 43, no. 1, pp. 181-190, 2002.

[39] J. Clottes, "Return to Chauvet cave," in Excavating the Birthplace of Art: the First Full Report, Thames and Hudson, London, UK, 2003. 

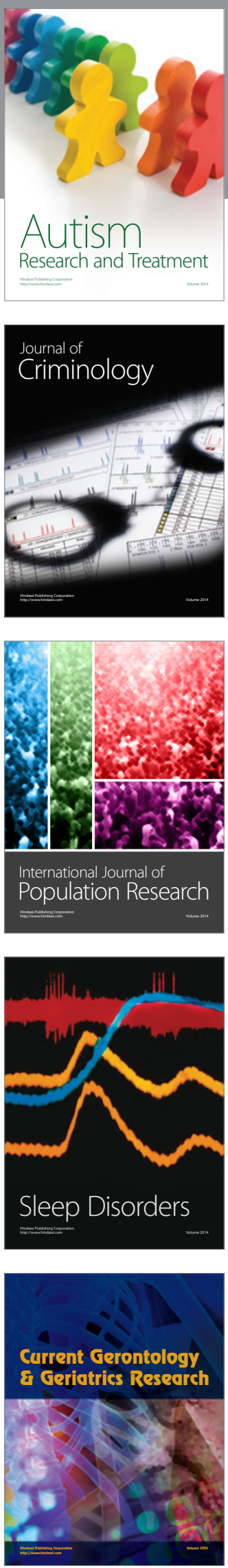
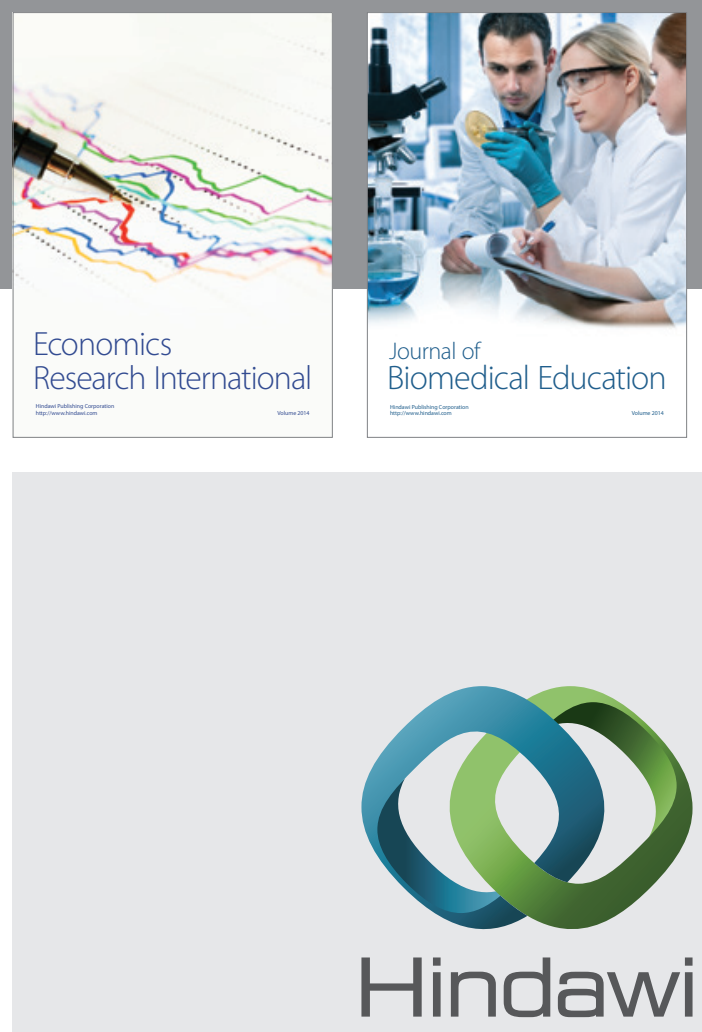

Submit your manuscripts at

http://www.hindawi.com
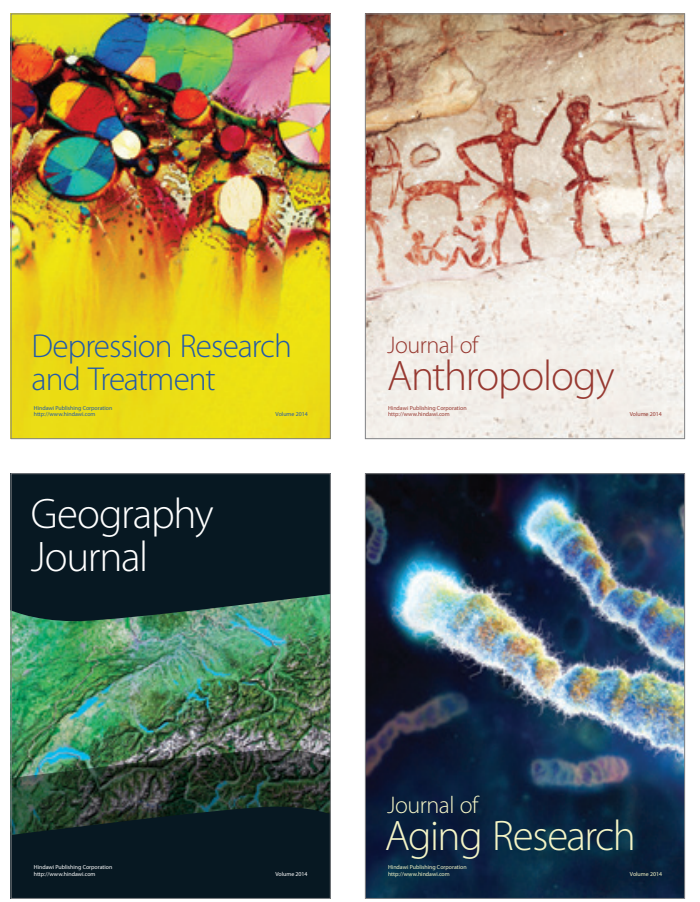
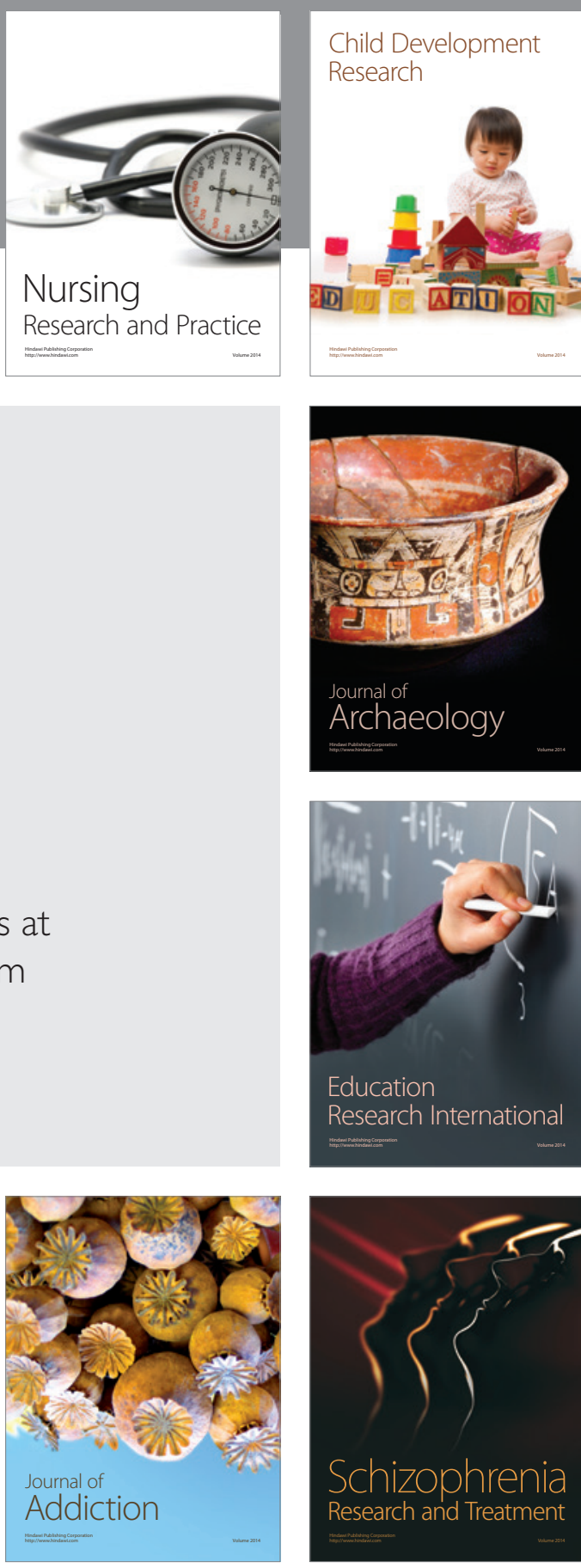

(D)
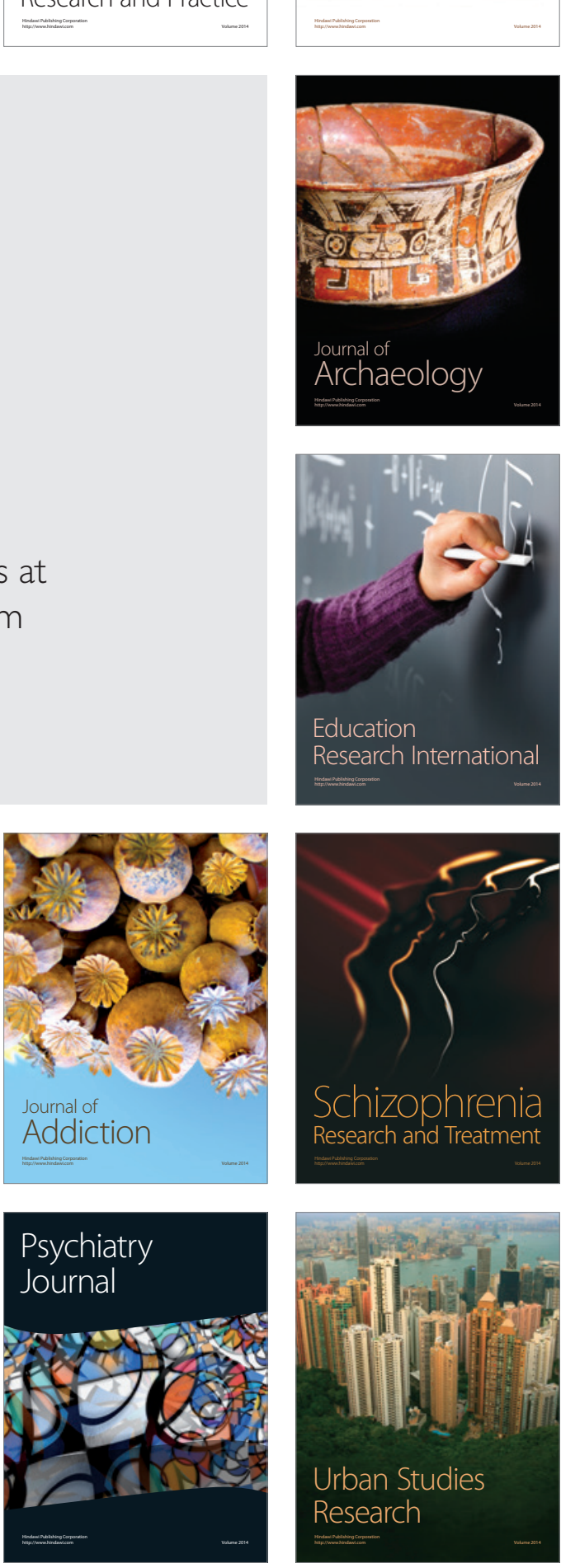